\title{
Avaliação ultra-sonográfica transvaginal na incontinência urinária feminina
}

\section{Transvaginal ultrasound in the assessment of female stress urinary incontinence}

Autor: Fernando Rocha de Oliveira

Orientador: Prof. Dr. José Geraldo Lopes Ramos

Tese apresentada ao Programa de Pós-Graduação em Medicina: Ciências Médicas, para obtenção do título de Doutor na Universidade Federal do Rio Grande do Sul, em 7 de julho de 2005.

A ultra-sonografia vem sendo o estudo de imagem mais utilizada para avaliação complementar da incontinência da urinária feminina (IUF). Apesar de ser um exame de fácil execução há poucos estudos no nosso meio avaliando os parâmetros na avaliação diagnóstica. O objetivo do estudo foi determinar o papel da ultra-sonografia transvaginal (USTV) na propedêutica da incontinência urinária (IU), avaliando a hipermobilidade do colo vesical (HCV) e a medida do diâmetro uretral interno (MDUI) nas pacientes continentes e incontinentes. Foi realizado estudo caso-controle no qual se avaliaram 94 mulheres incontinentes e 96 continentes. Avaliaram-se HCV através do sistema de coordenadas (x-y) e MDUI na sua porção medial. As pacientes com IU de esforço apresentaram mobilidade do colo vesical significativamente maior que as mulheres continentes e que as pacientes com IU de urgência e mista $(p<0,05)$. As pacientes com o diagnóstico de defeito esfincteriano uretral intrínseco
(DEUI) apresentaram significativamente diâmetros uretrais maiores que os controles e que as pacientes incontinentes sem este diagnóstico $(\mathrm{p}<0,05)$. Setenta e oito por cento $(78,7 \%)$ das pacientes com IU esforço apresentaram mobilidade do colo vesical superior a $10 \mathrm{~mm}$ e 91,7 \% das pacientes com DEUI apresentaram medida do diâmetro uretral superior a $5 \mathrm{~mm}$. HCV maior que 10 $\mathrm{mm}$ apresentou sensibilidade de $78,7 \%$ e especificidade de $72,7 \%$ para IU esforço. Diâmetros uretrais maiores que $6 \mathrm{~mm}$ apresentaram sensibilidade de $91,7 \%$ e especificidade de $75,6 \%$ para DEUI. Concluímos que a USTV tem um importante papel na avaliação das pacientes com IU de esforço e nas pacientes com DEUI.

PALAVRAS-CHAVE: Ultra-sonografia transvaginal; Incontinência urinária feminina; Hipermobilidade do colo vesical; Diâmetro uretral interno

Resumo de Tese

\section{Estudo comparativo entre a histerossonografia e outros métodos de avaliação da cavidade uterina em pacientes com abortamento espontâneo de repetição}

\section{A comparative study between histerosonography and other methods of evaluation of the uterine cavity in patients with recurrent miscarriage}

Autor: Hélio Antonio Guimarães Filho

Orientador: Profa. Dra. Rosiane Mattar

Co-orientador: Prof. Dr. Antonio Fernandes Moron

Dissertação de Mestrado apresentada ao Departamento de Obstetrícia da Universidade Federal de São Paulo Escola Paulista de Medicina (UNIFESP-EPM), em 24 de outubro de 2005.

Objetivos: avaliar a acurácia e tolerabilidade da histerossonografia (HS) e da histerossalpingografia (HSG) para o diagnóstico de alterações da cavidade uterina em pacientes com abortamento espontâneo de repetição (AER). Pacientes e Métodos: sessenta pacientes com passado de três ou mais AER foram avaliadas por HS, HSG e histeroscopia (HTC). Os achados foram divididos em três grupos: sinéquias, lesões polipóides e alterações da forma. A HTC foi considerada o padrão-ouro. A concordância dos achados da HS e HSG foi avaliada pelo coeficiente Kappa e sua significância foi testada. O nível de significância adotado foi de $0,05(\alpha=5 \%)$. Foram calculadas as medidas de sensibilidade, especificidade, valor preditivo positivo e negativo para cada um dos métodos. Resultados: observou-se a presença de anomalias uterinas em $23(38,3 \%)$ pacientes, sendo $16(26,7 \%)$ sinéquias, $3(5,0 \%)$ lesões polipóides e $8(13,3 \%)$ altera- ções da forma. A acurácia da HS e HSG foi, respectivamente, de 90,9 e $85,2 \%$, ambas estatisticamente significativas. Todavia, comparativamente à HSG, a HS foi superior quanto à sensibilidade $(90,5 \%$ vs $75,0 \%)$ e concordância com o padrão-ouro (Kappa $=81 \%$ vs. Kappa $=68 \%$ ). Em relação à percepção de dor, a HS apresentou melhor tolerabilidade, com diferença estatisticamente significativa em relação aos outros métodos, enquanto a HSG foi o exame menos tolerado. Conclusões: observou-se elevada acurácia da HS e da HSG para a detecção de anormalidades da cavidade uterina. Todavia, comparativamente à HSG, a HS obteve níveis superiores de sensibilidade e concordância com a histeroscopia.

PALAVRAS-CHAVE: Aborto recorrente; Histerossonografia; Histerossalpingografia; Histeroscopia; Tolerabilidade 